Bulletin d'Histoire Contemporaine de l'Espagne

$54 \mid 2020$

Les espaces du politique dans l'Espagne du Trienio liberal (1820-1823)

\title{
Les espaces du politique dans l'Espagne du Trienio liberal (1820-1823). Hommage au professeur Alberto Gil Novales
}

Introduction

Elisabel Larriba y Pedro Rújula

\section{(2) OpenEdition}

Journals

Edición electrónica

URL: http://journals.openedition.org/bhce/1307

DOI: 10.4000/bhce.1307

ISSN: 1968-3723

Editor

Presses Universitaires de Provence

Edición impresa

Fecha de publicación: 1 enero 2020

ISSN: 0987-4135

Referencia electrónica

Elisabel Larriba y Pedro Rújula, « Les espaces du politique dans l'Espagne du Trienio liberal

(1820-1823). Hommage au professeur Alberto Gil Novales », Bulletin d'Histoire Contemporaine de l'Espagne [En línea], 54 | 2020, Publicado el 01 julio 2020, consultado el 31 diciembre 2020. URL http://journals.openedition.org/bhce/1307 ; DOI : https://doi.org/10.4000/bhce.1307

Este documento fue generado automáticamente el 31 diciembre 2020.

Bulletin d'histoire contemporaine de l'Espagne 


\title{
Les espaces du politique dans l'Espagne du Trienio liberal (1820-1823). Hommage au professeur Alberto Gil Novales
}

Introduction

\author{
Elisabel Larriba y Pedro Rújula
}

1 En noviembre de 2016 desapareció uno de los más importantes historiadores españoles: el profesor Alberto Gil Novales. Desde la Guerra de la Independencia hasta Antonio Machado, pasando por Joaquín Costa, no había aspecto de la historia de España que no suscitara por su parte un interés que, en muchas circunstancias, le llevó a profundizar el tema y ofrecer a la comunidad científica aportaciones de hondo calado ${ }^{1}$.

2 Sin embargo, aunque siempre se negó a limitar su curiosidad intelectual y su labor de investigador a cuatro años del siglo XIX, se hizo no un especialista, sino el especialista del Trienio liberal con publicaciones verdaderamente magistrales: Las Sociedades patrióticas.... ${ }^{2}$, Rafael del Riego. La Revolución de 1820, día a día ${ }^{3}$, El Trienio liberal ${ }^{4}$ y el Diccionario biográfico del Trienio liberal ${ }^{5}$, completado e incorporado en su monumental Diccionario biográfico de España (1808-1833)6.

3 Al acabar la lectura de su obra maestra, Las Sociedades...., fundada en una documentación nada común con sus siete páginas de referencias a archivos, más de 2000 títulos de bibliografía (entre los cuales figuran los de un sinnúmero de hojas sueltas y folletos rastreados en las cajas -entonces no inventariadas- de la serie raros de la Biblioteca Nacional de España) y 680 cabeceras de periódicos identificados, nos quedamos con la impresión de que Alberto Gil Novales lo vio todo y lo dijo todo sobre lo que se denominó entonces "la segunda revolución española". Y efectivamente, vio todo lo que se conserva en España. Quedaron fuera de su radio de acción las fuentes diplomáticas extranjeras, entonces mucho más difíciles de acceso que hoy. Ese hueco lo fueron cubriendo otros accediendo a la correspondencia del Nuncio Apostólico en Madrid, Giustiniani, conservada en el Archivio Segreto Vaticano (y que explotó primero 
Gérard Dufour para su obra Juan Antonio Llorente en France 7 , y luego Beatriz Sánchez Hita para su Clararrosa ${ }^{8} \mathrm{y}$, sobre todo Maximiliano Barrio Gozalo, para su estudio sobre La Santa Sede y los obispos españoles en el Trienio liberal ${ }^{9}$. $\mathrm{O}$ a los despachos dirigidos a su ministro por los sucesivos embajadores de Francia (también utilizados por Dufour para su Llorente..., y luego Jordi Roca Vernet ${ }^{10}$ y Sánchez Martín ${ }^{11}$ en su tesis sobre Riego). Y, de paso, es de desear que la profesora Alicia Laspra prosiga para el Trienio la investigación en el Foreign Office que tan buenos resultados le dio para la Guerra de la Independencia ${ }^{12}$ y que se investiguen también las correspondencias diplomáticas de los representantes en España del zar, del emperador de Austria y del rey de Prusia.

Como decíamos, Alberto Gil Novales vio todo lo que se encontraba en España, y el fondo erudito que arma su obra lo pone de manifiesto a cada página. Y, pese a todo, no lo dijo todo. Muchas veces se contentó, como hizo en su inconmensurable Las Sociedades Patrióticas, con repartir cartas, explicar las reglas y proponer la dinámica del juego invitándonos a establecer conexiones, tender puentes, seguir pistas, abrir otras, en esta dialéctica científica tan cara a los hombres de su generación.

Esto es lo que pretendieron (y lograron) hacer los que participan en este número monográfico del Bulletin d'Histoire Contemporaine de l'Espagne como homenaje de todos y cada uno al maestro desaparecido. En efecto, por más importantes que fueron las sociedades patrióticas como centros de debates y de definición de objetivos políticos, no fueron los únicos lugares en los que se forjó la opinión pública que no era una "prostituta vendida a intereses particulares" como pretendía Napoleón ${ }^{13}$ sino la "señora del mundo", en palabras de El Cetro constitucional ${ }^{14}$, o la "Reina de los pueblos", según se podía leer en $\mathrm{El} \mathrm{Amigo} \mathrm{del} \mathrm{Pueblo}{ }^{15}$. Todos los espacios públicos (desde las iglesias, con sus púlpitos y confesionarios hasta los teatros, pasando por los cafés, las tertulias, centros docentes, etc...) estuvieron invadidos por el furor político. Los espacios privados (y muy privados) también, como prueba la afirmación a menudo reiterada en la prensa liberal de los años 1821-1822 de que las hermosas se negaban a entregar sus corazones a serviles.

6 Existe un delicioso texto de Ramón Mesonero Romanos titulado Mis ratos perdidos o ligero bosquejo de Madrid, publicado en 1822, en el que el autor recorre diversos espacios públicos de la capital española durante el Trienio liberal. Su ironía de observador distante le permite ofrecer una interesante imagen de la vida cotidiana de los madrileños durante el período constitucional. En uno de sus cuadros, dedicado a la Puerta del Sol, ante la multitud de corros y la intensidad de las conversaciones, se refiere a este populoso lugar en el centro de la ciudad como "aquel respetable congreso". ${ }^{16}$ Es indudable que utiliza la expresión con ironía ${ }^{17}$ por lo informal de las conversaciones que tenían lugar allí, al aire libre, y por las dispares razones que explicaban la presencia de toda aquella gente en la plaza. Sin embargo, cuando detalla las conversaciones de las que fue testigo nuestro interés crece. En un lugar se hablaba de las cotizaciones del papel moneda. En otro discutían sobre la actualidad política internacional, en concreto sobre si los austríacos terminarían invadiendo o no el reino de Nápoles. Finalmente se adentró en otro corro, vecino al café de Lorencini, donde la conversación giraba en torno a la última moda masculina de París.

7 Sin pretenderlo, Mesonero nos da la oportunidad de adentrarnos en la calle madrileña y de comprobar: Que durante el Trienio la política desborda los muros de las instituciones e invade el espacio de las ciudades. Que en el nuevo régimen la política circula e impregna la vida cotidiana de la población. Que no hay quien viva sin que en 
su día a día participe de las visiones políticas del momento. La libertad de movimientos, las facilidades para expresar la opinión, los efectos económicos de las medidas del gobierno, la necesidad de concurrir a las urnas para elegir representantes, la organización de la milicia, etc., todo conspira para traer la política a la vida de los ciudadanos.

8 No obstante, durante el Trienio, la política no se desarrolló en un único plano ni se redujo a lo que sucedía en el espacio oficial o institucional. Existían, es cierto, unos espacios institucionales de la política. Son fáciles de identificar, porque se desprenden de la Constitución y del nuevo ordenamiento legal: el Rey, las Cortes, el Gobierno y los Ayuntamientos, son los principales de ellos. También la presencia territorial del Estado con los capitanes generales y los jefes políticos. Pero hay mucho más.

9 En un nivel inferior nos encontramos con otras dimensiones de lo político que también se desprenden del marco jurídico, como son la milicia nacional y la prensa. La primera constituye una forma de movilizar a la sociedad en defensa del régimen poniendo las armas en su mano. La segunda es un artefacto ideológico de enorme potencia que abría el espacio público a la discusión de ideas diferentes y que debía convertirse en pieza clave para formar una ciudadanía firme y bien informada. En ambos casos, milicia e imprenta, se revelarán como potentísimos instrumentos de politización.

10 El tercero de los niveles, ya informal, pero que gira en torno a establecimientos reconocibles por su función, lo encontraríamos en los espacios de sociabilidad. Así podemos hablar de la iglesia, los cafés, los teatros y de las sociedades patrióticas. Lugares donde se intercambia información, se establecen relaciones y se participa compartiendo actitudes e ideas. A pesar de su pluralidad, y de la escasa regulación de la actividad que en ellos tiene lugar, se encuentran muy cerca de la conciencia de los ciudadanos e impactan directamente sobre la sensibilidad y la experiencia de quienes los frecuentan.

11 Pero aún existe un cuarto ámbito de lo político mucho más difuso y más informal que se desintegra en los espacios y en los medios a través de los que circulan los mensajes. Es la política en los márgenes. Unos márgenes de muy distinta condición: márgenes sociales, márgenes espaciales e, incluso, márgenes ideológicos.

12 Explorar los márgenes sociales supone adentrarse en la política sin detenerse en la frontera de las élites. Ir más allá de aquellos actores del Antiguo Régimen que perviven en política o de las nuevas élites burguesas que se incorporan con fuerza al espacio constitucional y que conocen bien los instrumentos jurídicos que sustentan al nuevo Estado. En realidad, ¿hasta donde llegó socialmente la política en el Trienio? ¿Las formas políticas del liberalismo, descendieron e impregnaron a las capas sociales más bajas? ¿Cómo percibieron estas la propuesta política de la Constitución? ¿Sintieron como propios los derechos proclamados en el código, o fueron interpretados como un conjunto de fórmulas abstractas y lejanas? Y, en este último caso, ¿dónde identificaron la política del liberalismo las clases populares?

13 Explorar los márgenes espaciales nos lleva a preguntarnos dónde se hizo la política. Es evidente que las Cortes son el espacio central de la vida pública. Pero ¿hasta donde llegó, en términos espaciales, la política del Trienio? En el espacio urbano, ¿donde se hizo la política? La política ¿subió a los altares, bajó a los mercados, desfiló por las calles, se difundió en los patios de vecinos, en las plazas o en los talleres? Y, si fue así, cómo lo hizo, quienes fueron los protagonistas, cuáles los instrumentos. Y más allá de las ciudades y cabeceras administrativas, ¿hasta donde llegó la influencia del 
liberalismo? Es evidente que los nuevos ayuntamientos podrían romper con los equilibrios de poder locales, pero ¿lo hicieron realmente? Y, fuera de los ayuntamientos, ¿qué presencia tuvo la política liberal en la vida de los habitantes del campo? ¿Cómo llegaron hasta ellos las noticias, las novedades, las informaciones?

Y finalmente, conviene explorar también los márgenes ideológicos. Sin lugar a dudas, el liberalismo gaditano inspiró el desarrollo político-institucional del Trienio, pero ¿cabe en él toda la política del Trienio? ¿En qué terreno jugó sus cartas la contrarrevolución? ¿Descendió a la arena política del liberalismo o intentó librar la batalla fuera de ella? Y si fue así, si los contrarrevolucionarios trataron de sacar la batalla de las instituciones -instrumentando la corona, valiéndose de la religión o recurriendo a las armas- ¿Cuál fue el resultado? Por otro lado, dada la fórmula monárquica asumida por los liberales españoles, ¿cuál fue la suerte de los proyectos republicanos?

En definitiva, para comprender mejor el Trienio hay que reevaluar todos los ámbitos en los que se hizo la política, dotar de complejidad al análisis, hacerlo multipolar, alejarnos un poco de las sedes oficiales del poder y escuchar lo que dice y opina la gente sobre el terreno, allí donde se configura la opinión pública. También cabe adentrarse en los espacios privados, íntimos,

Así mismo, conviene distanciarnos un poco de Madrid para comprobar el efecto que están teniendo las medidas liberales en otras ciudades, entre los campesinos o entre las oligarquías locales. Y también evaluar la difusión de ideas desde los núcleos emisores instituciones, prensa, personas etc.- hasta los puntos de recepción. También cabe explorar los espacios privados, que no son los más fáciles de aclarar, y, en esta guerra civil en la que acabó el Trienio liberal, convendría saber si, como pasó en épocas posteriores y como se puede sospechar, hubo o no fracturas dentro de las propias familias y, de ser el caso, cuándo, cómo y por qué se produjeron.

Para adentrarse por estas vastas tierras, hemos llamado a destacados especialistas que, todos, aceptaron con entusiasmo nuestro invite y nos proponen el resultado de sus investigaciones. De todo no será cuestión en este monográfico. Pero hay que dar tiempo al tiempo. Y por ello, concluiremos con estas palabras clásicas de la prensa: "se continuará".

\section{NOTAS}

1. Pedro Rújula (coord.), Alberto Gil Novales (1930-2016). Los mundos del historiador, Huesca, Instituto de Estudios Altoaragoneses, 2019.

2. Las Sociedades patrióticas (1820-1823). Las libertades de expresión y de reunión en el origen de los partidos políticos, Madrid, Editorial Tecnos, 1973, 1290 p. en dos tomos.

3. Rafael del Riego. La Revolución de 1820, día a día. Cartas, escritos y discursos. Prólogo, biografía sucinta, notas y recopilación de documentos por Alberto Gil Novales, Madrid, Editorial Tecnos, 1976, 229.

4. Siglo XXI, 1980, 146 p. (2 a edición: 1989).

5. Madrid, El Museo Universal, 1991, 737 p. 
6. Diccionario biográfico de España (1808-1833). De los orígenes del liberalismo a la reacción absolutista, Madrid, Fundación MAPFRE, 2010, 3406 p. en tres volúmenes.

7. Juan Antonio Llorente en France. Contribution à l'étude du libéralisme chrétien en France et en Espagne au début du XIX ${ }^{e}$ siècle, Genève, Droz éditeur, 1982.

8. José Joaquín de Clararrosa y su Diario gaditano (1820-1822). Ilustración, periodismo y Revolución en el Trienio liberal, Cádiz, UCA - Fundación Centro de Estudios Constitucionales 1812, 2009.

9. Roma, Instituto español de Historia eclesiástica, 2015. Reedición aumentada en 2017.

10. La Barcelona revolucionària i liberal: exaltats, milicians $i$ conspiradors, Barcelona, Fundació Noguera, 2011.

11. Rafael del Riego, símbolo de la Revolución liberal, tesis doctoral, Alicante [2016], en línea www.eltallerdigital.com .

12. La intervención británica en Asturias durante la Guerra de la Independencia (1808-1813), Universidad de Oviedo, 1992.

13. Correspondance inédite de Napoléon $I^{e r}$ conservée aux Archives de la Guerre publiée par Ernest Picard, lieutenant-colonel d'artillerie breveté et Louis Tueley, bibliothécaire-archiviste au Ministère de la Guerre. [Ouvrage] publié sous la direction de la Section Historique de l'Etat-Major de l'Armée, Paris, Henri Charles-Lavauzelle, 1919-1925, III, p. 193.

14. "Artículo remitido". En El Cetro constitucional, n 4, 1820: "Lejos de pensar nosotros que la opinión nada valga, la respetamos como la señora del mundo. - Reprimida cobra fuerzas hasta romper los diques que la contienen, y entonces a guisa de un torrente allana y arrebata cuanto encuentra delante" (19).

15. Tal fue la expresión utilizada en un artículo publicado en $1822\left(n^{\circ} 5\right)$ y titulado "La opinión es la reina del mundo" (112-120, cita p. 92.)

16. Imprenta de don Eusebio Álvarez, Madrid, 1822, p. 28.

17. Aparte de sus connotaciones parlamentarias, la RAE da cuenta de otras acepciones que van desde aquellas que hacen referencia a la reunión de personas hasta la que remite a una relación carnal. M. Núñez Taboada, Diccionario de la Lengua Castellana, Librería de Seguin, París, 1825, cif. "congreso": "Junta de varias personas para deliberar sobre algún negocio y más comúnmente para tratar asuntos de gobierno", vol. I, p. 366.

\section{AUTORES}

\section{ELISABEL LARRIBA}

Aix-Marseille Université, CNRS, 7303, UMR TELEMME

PEDRO RÚJULA

Universidad de Zaragoza 